\title{
Factors Impacting Water Quality of a Small Stream in a Mountain Forest
}

\author{
Masatomo Nakayama \\ Department of Civil Engineering and Management, Tohoku Institute of Technology, Sendai 982-8577, Japan
}

Received: October 29, 2015 / Accepted: November 16, 2015 / Published: December 10, 2015

\begin{abstract}
Recent improvements to sewerage systems have meant that the relative contribution of point sources of pollution to the overall pollutant loads of streams has decreased markedly. Consequently, the potential increase in non-point source pollution means that it may be necessary to focus more on pollution loads from non-point sources in the future. This study examined pollution loads from non-point sources in streams flowing through forested areas. In addition, the relationship between runoff and pollution loads was also clarified. The small streams in the Tohoku University Botanical Gardens, in Sendai city, Japan, were sampled during a dry weather period and their water quality parameters were characterized. Chemical Oxygen Demand (COD) concentration increased with distance downstream, possibly because the soils in downstream areas contained high amounts of organic matter. Conversely, the concentration of nitrate nitrogen $\left(\mathrm{NO}_{3}-\mathrm{N}\right)$ decreased with distance downstream, probably because upstream soils were generally in an oxidized state while those further downstream were reduced. COD concentration increased with air temperature, while $\mathrm{NO}_{3}-\mathrm{N}$ levels decreased with an increase in air temperatures.
\end{abstract}

Key words: Dry weather, forest stream, non-point source.

\section{Introduction}

Pollutant load runoff from point sources decreases as sewer systems improved, resulting in an increase in pollutant load runoff from non-point sources relative to point sources. Thus, understanding pollutant load runoff from non-point sources is becoming more important [1].

The aim of this study is to determine the characteristics of runoff from a forest catchment, where non-point source pollutant loading predominates for a stream. Water quality and stream discharge are known to differ between periods of dry and wet weather. In this study, water samples were taken during periods of dry weather in order to determine water quality in dry weather.

Corresponding author: Masatomo Nakayama, Ph.D., main research field: water environment.

\section{Materials}

\subsection{Studied Stream}

The studied site was the largest of three streams flowing through the Tohoku University Botanical Gardens (area of 520,000 $\mathrm{m}^{2}$ ) in Aoba Ward, Sendai city, Miyagi prefecture in Japan (Fig. 1). The vegetation of this area is composed of momi fir forests, as well as forests of konara oak, Japanese red pine and Japanese cedar, reed beds and other species.

Three streams (Urasawa, Honsawa and Fukasawa) flow from southwest to northeast through this area. Water sampling was conducted on Honsawa, which has the largest catchment area (18.9 ha) among the streams flowing inside the botanical garden.

Water sampling was conducted from 2010 to 2012 at five points along a stretch of Honsawa labeled e through a from upstream to downstream. Water flowing from e to a travelled a distance of $520.9 \mathrm{~m}$ in $2.74 \mathrm{~h}$ during this study. Table 1 shows distances between individual sampling points. 


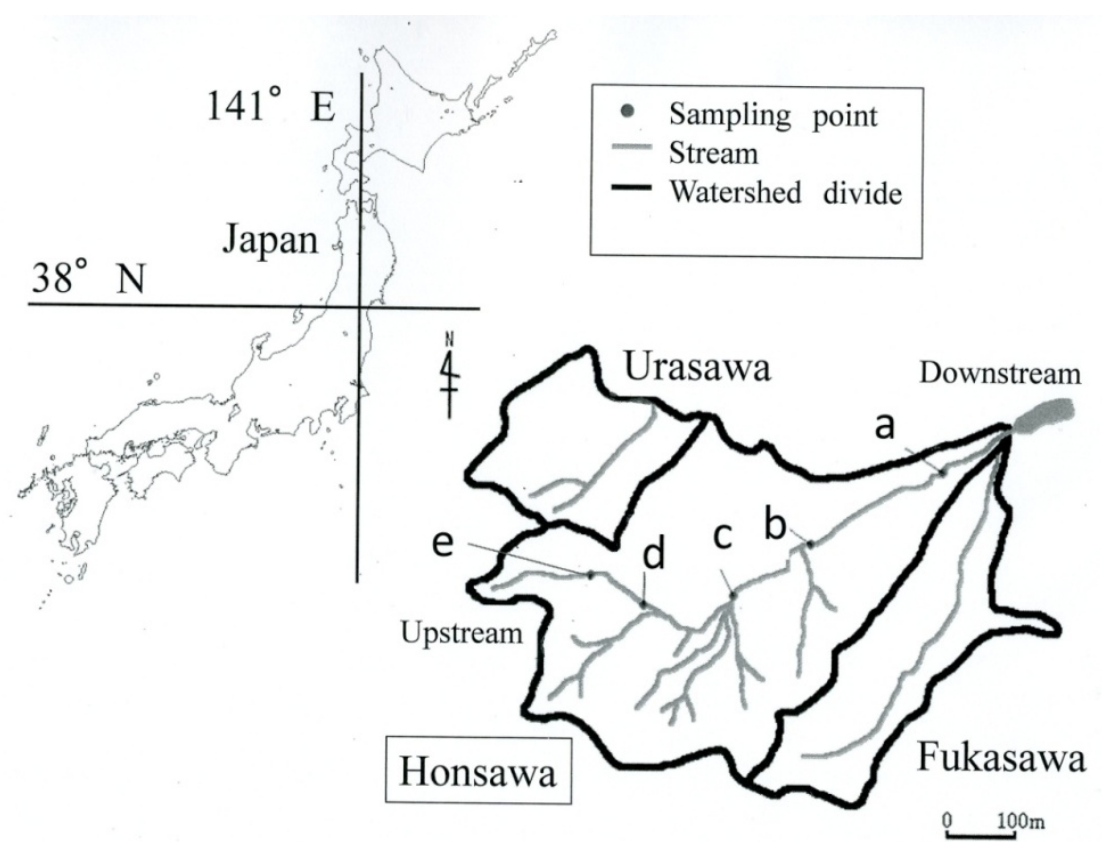

Fig. 1 Water sampling points on Honsawa.

Table 1 Distance and stream flow characteristics between sampling points.

\begin{tabular}{lrrrrrrrr}
\hline & \multicolumn{1}{c}{ a-b } & \multicolumn{1}{c}{ b-c } & \multicolumn{1}{c}{ c-d } & \multicolumn{2}{c}{ d-e } & Total \\
\hline Distance (m) & 136.00 & 32.00 & 69.60 & 67.70 & 100.00 & 46.70 & 68.90 & \\
Flow velocity (cm/S) & 3.30 & 18.40 & 6.10 & 4.30 & 7.90 & 8.50 & 6.60 & \\
Flowing time (h) & 1.14 & 0.05 & 0.32 & 0.44 & 0.35 & 0.15 & 0.29 & \\
Distance (m) & 136.00 & & 169.30 & & 146.70 & & 68.90 & 520.90 \\
Flowing time (h) & 1.14 & & 0.80 & & 0.50 & & 0.29 & 2.74 \\
\hline
\end{tabular}

\subsection{Study Method}

Although there are several tributaries as shown on the map of the study stream, there is no water flow through in the tributaries during periods of dry weather, therefore, the increase in stream discharge is due to groundwater inflow. And the characteristics of groundwater and the soil through which the groundwater flows must be understood in order to determine the change in water quality of a stream during periods of dry weather. Oxidation-Reduction Potential (ORP) electrodes were placed on the stream bank at each sampling point to measure redox potential $\left(\mathrm{E}_{\mathrm{h}}\right)$. Soil samples were collected at sampling points and assayed for organic matter content. The values obtained were used to examine its relationship with stream water quality. The study was conducted for a period of 3 years from 2010 to 2012.

\subsection{Measured Parameters}

At each sampling point, water temperature, air temperature, discharge and redox potential $\left(\mathrm{E}_{\mathrm{h}}\right)$ were measured. The following water quality parameters were determined: Chemical Oxygen Demand (COD) (measured as CODMn), $\mathrm{Cl}^{-}$, turbidity, nitrogen and phosphorus. For the nitrogen, the concentrations of $\mathrm{T}-\mathrm{N}, \mathrm{NH}_{4}-\mathrm{N}, \mathrm{NO}_{2}-\mathrm{N}$ and $\mathrm{NO}_{3}-\mathrm{N}$ were measured. For the soil, the mass of volatile solids (loss on ignition) was analyzed and taken as the mass of organic matter.

\section{Result and Discussions}

\subsection{Stream Discharge, COD and Organic Matter}

Fig. 2 shows the stream discharge at each sampling point. Stream discharge increases with position downstream [2, 3]. There are several tributaries to Honsawa, but water seldom flows in those tributaries 


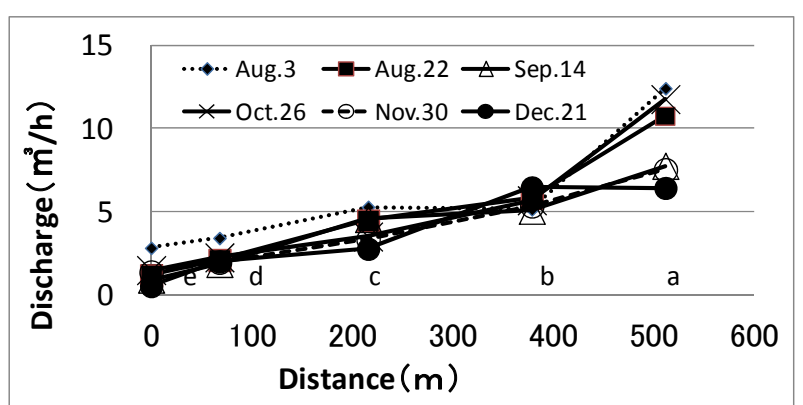

Fig. 2 Variations in stream discharge during 2012.

during periods of dry weather. Therefore, the increase in stream discharge is due to the inflow of groundwater. COD tends to increase over the stretch of the stream (Fig. 3).

The mass of organic matter as a percent of soil at depth of 0-30 cm were shown in Fig. 4. The amount was small at the upstream point e and increased at midstream to downstream points. There were many particles appearing to be derived from crushed rocks in the upstream soil (point e). In contrast, organic content from fallen leaves was comprised a greater proportion of the particles in the midstream and downstream soils. From observations of soil, it can be nferred that the downstream soil contained higher amounts of organic matter than the upstream soil and that the COD increased downstream because of inflow into the stream of groundwater that had passed through soil layers with high organic content.

\section{$3.2 \mathrm{NO}_{3}-\mathrm{N}$ (Nitrate-Nitrogen) and $\mathrm{E}_{h}$}

The $\mathrm{NO}_{3}-\mathrm{N}$ concentration (Fig. 5) decreases with the downstream flow. The $E_{h}$ of the soil measured at a depth of $25 \mathrm{~cm}$ from the surface (Fig. 6) shows that the upstream and midstream points from e to $\mathrm{c}$ are in an oxidized state, while the downstream points are in a reduced state $[4,5]$. From these findings, it can be inferred that nitrification progressed at point e upstream, resulting in high $\mathrm{NO}_{3}-\mathrm{N}$ and $\mathrm{NO}_{3}-\mathrm{N}$ inflowing downstream of point e were small, as shown by the lower $\mathrm{NO}_{3}-\mathrm{N}$.

\subsection{Concentration Change over Distance}

The change in concentration of a water quality

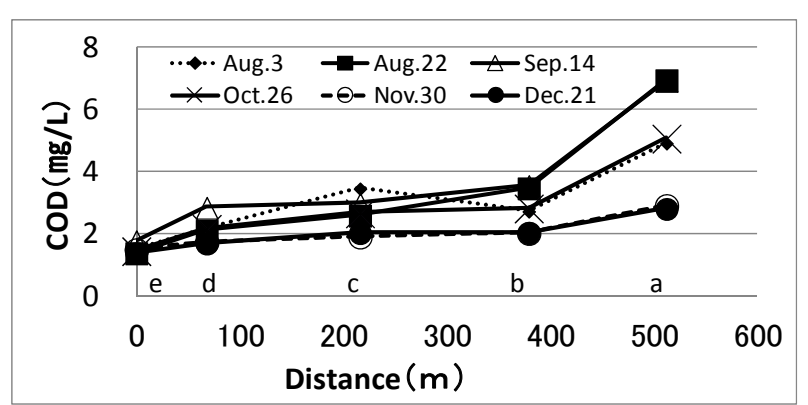

Fig. 3 COD at sampling points in 2012.

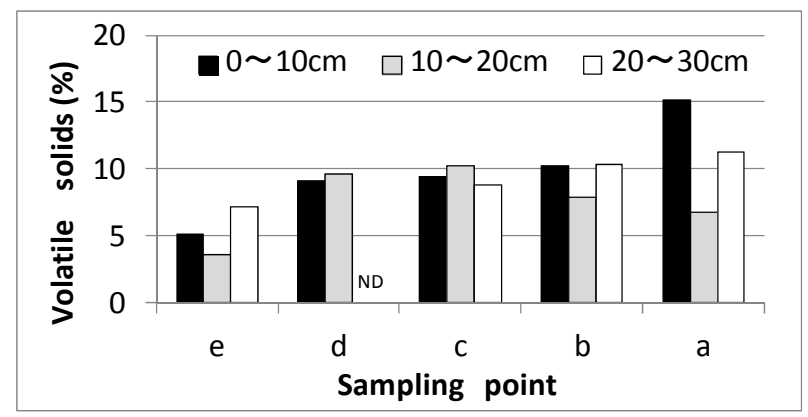

Fig. 4 Organic matter in the soil at depth of $0-30 \mathrm{~cm}$ in 2011.

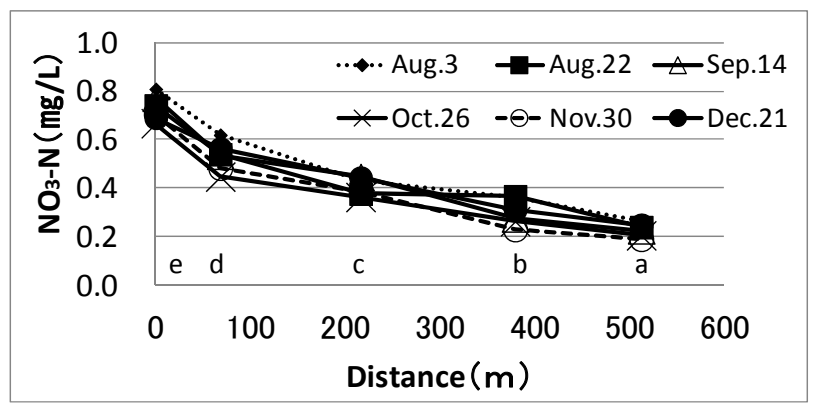

Fig. $5 \quad \mathrm{NO}_{3}-\mathrm{N}$ at sampling points in 2012.

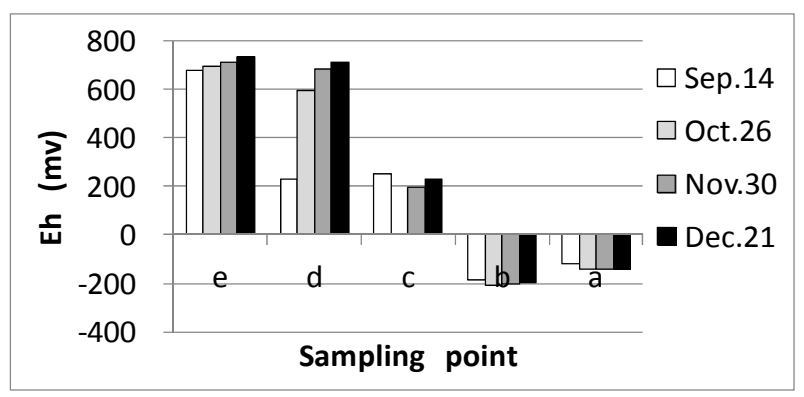

Fig. $6 E_{h}$ at a depth of $25 \mathrm{~cm}$ at each sampling point in 2012.

parameter over a stretch of a stream, which represents the change in concentration over distance is calculated by the Eq. (1) [6].

Concentration change over distance $=\left(C_{\text {out }}-C_{\text {in }}\right) / D$

Where, $C_{i n}$ is concentration of water quality 
parameter at upstream sampling point, $C_{\text {out }}$ is concentration of water quality parameter at downstream sampling point, $D$ is distance between two points in the flow path.

A positive value indicates an increase in concentration over the distance traversed by the downstream flow, while a negative value indicates a decrease in concentration. Fig. 7 shows increasing COD. Increases in COD were observed over both the e-d interval in the upstream side and the b-a interval in the downstream side, and the increase over the b-a interval on the downstream side was greater. Over the season, greater increases were observed during the summer season when the air temperature was high. Fig. 8 shows the change in concentration over distance for $\mathrm{NO}_{3}-\mathrm{N}$. The concentration of $\mathrm{NO}_{3}-\mathrm{N}$ decreased over both intervals, but the decrease over the e-d interval on the upstream side was greater than the decrease over the b-a interval on the downstream side. Furthermore, the decrease in concentration was greater during the summer season when the air temperature is high $[7,8]$.

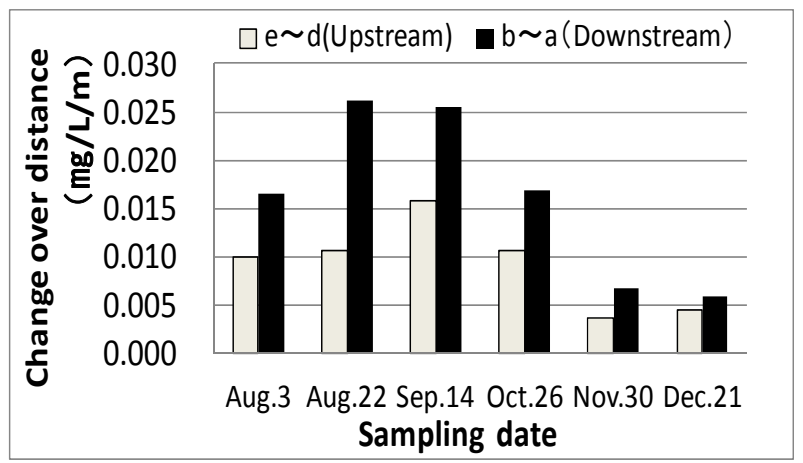

Fig. 7 Change in COD over $e$ to $d$ and $b$ to $a$.

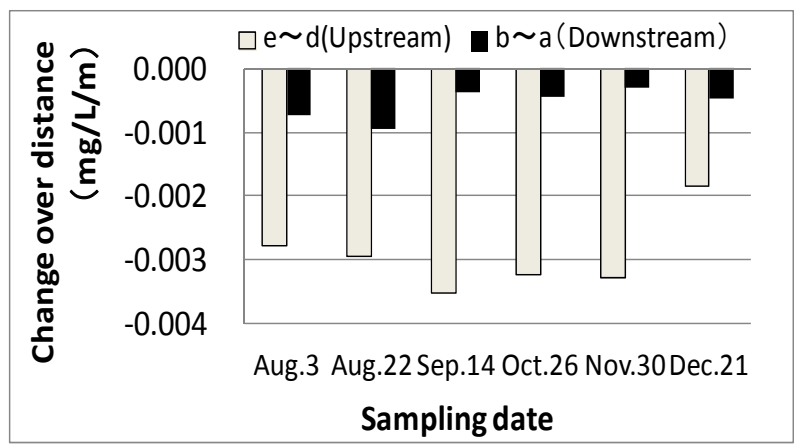

Fig. 8 Change in $\mathrm{NO}_{3}-\mathrm{N}$ over e to $\mathrm{d}$ and $\mathrm{b}$ to $a$.

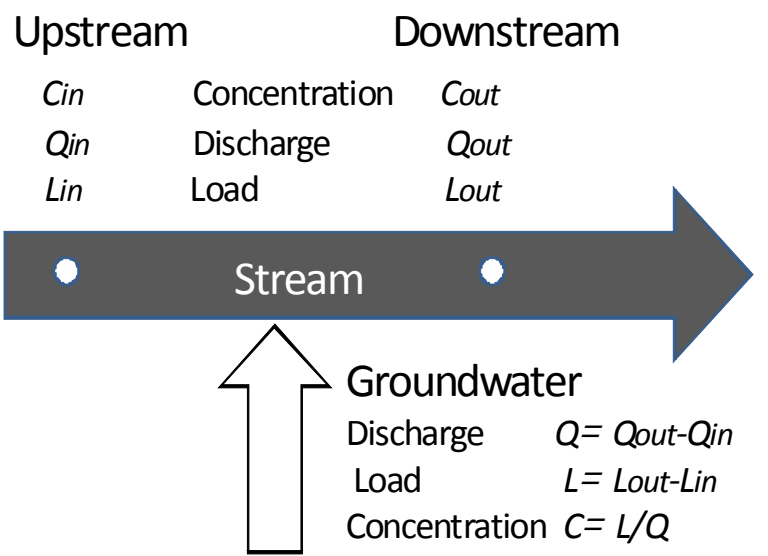

Fig. 9 Effect of concentration of water quality parameter in inflowing groundwater on the concentration of that parameter in the stream.

\subsection{Mass Balance}

Since the time required for water in the stream to flow from sampling point e to a was short at 2.74 hours, natural purification and nitrification during downstream flow is assumed to be negligible. Thus, changes in water quality are assumed to be more heavily influenced by the inflow of groundwater into the stream. Further, it is assumed that there is no recharge to groundwater from the stream. Based on these assumptions, the mean concentration of water quality parameters in the groundwater that inflows between the upstream and downstream sampling points can be calculated by Eq. (2) and illustrated in Fig. 9.

$$
C=L / D
$$

Where, $C$ is mean concentration of water quality parameter in inflowing groundwater;

$L$ is load of parameter in inflowing groundwater $\left(L_{\text {out }}-L_{\text {in }}\right)$;

$Q$ is discharge volume of inflowing groundwater $\left(Q_{\text {out }}-Q_{\text {in }}\right)$;

$Q_{\text {in }}$ is streamwater discharge volume at the upstream water sampling point;

$Q_{\text {out }}$ is streamwater discharge volume at the downstream water sampling point;

$L_{i n}$ is load of parameter in streamwater at upstream sampling point $\left(C_{i n} \times Q_{i n}\right)$; 


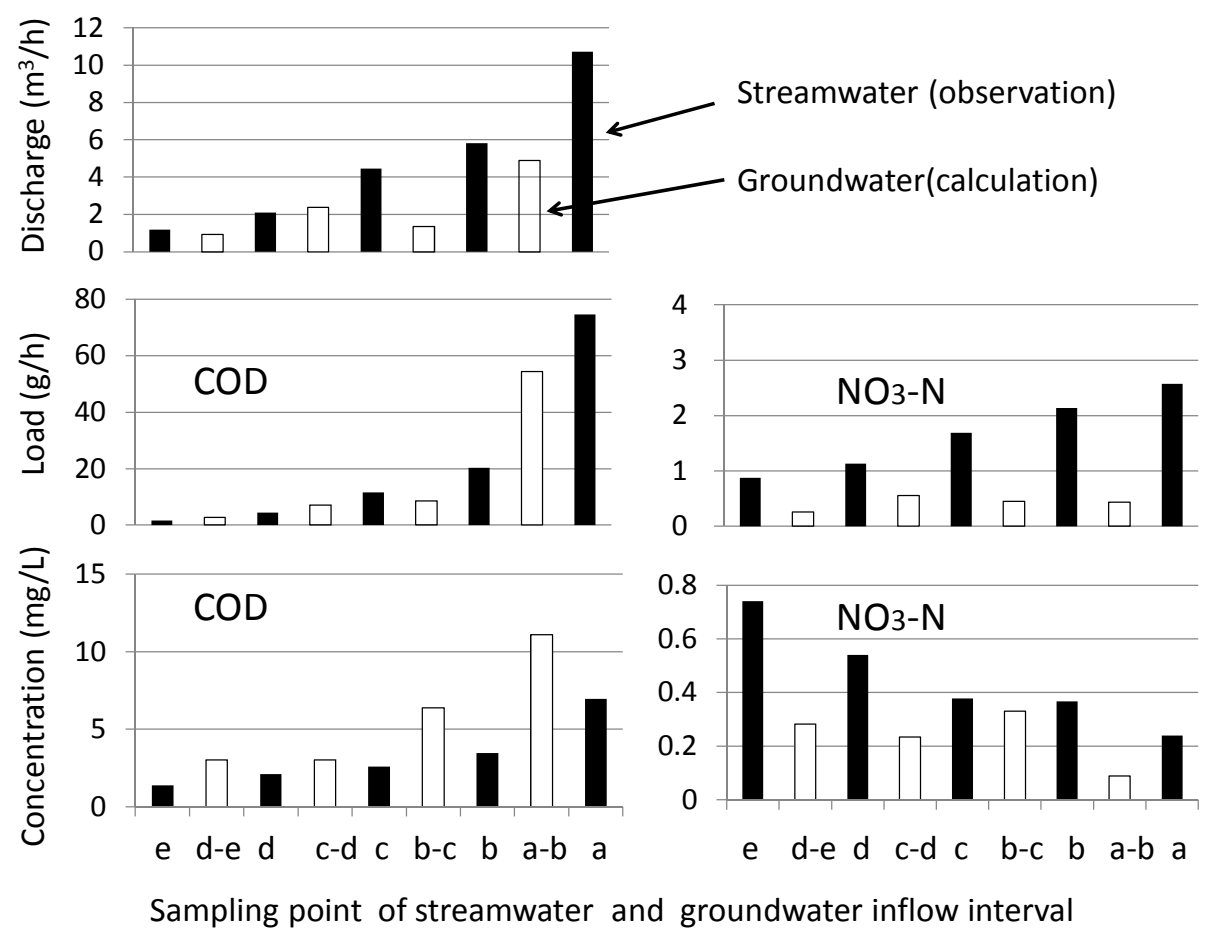

Fig. $10 \mathrm{COD}$ and $\mathrm{NO}_{3}-\mathrm{N}$ concentration of inflowing groundwater based on mass balance calculations in August 22, 2012.

Table 2 Correlation coefficient between air temperature and individual water quality parameters.

\begin{tabular}{llllll}
\hline \multirow{2}{*}{ Parameters } & \multicolumn{5}{l}{ Sampling point } \\
\cline { 2 - 6 } & $\mathrm{e}$ & $\mathrm{d}$ & $\mathrm{c}$ & $\mathrm{b}$ & $\mathrm{a}$ \\
\hline $\mathrm{COD}$ & 0.334 & 0.493 & 0.665 & 0.723 & 0.670 \\
$\mathrm{~T}-\mathrm{N}$ & -0.001 & -0.194 & 0.153 & 0.014 & 0.079 \\
$\mathrm{NO}_{3}-\mathrm{N}$ & -0.323 & -0.423 & -0.407 & -0.225 & -0.244 \\
$\mathrm{NH}_{4}-\mathrm{N}$ & -0.087 & -0.014 & 0.103 & 0.074 & -0.041 \\
\hline
\end{tabular}

$L_{\text {out }}$ is load of parameter in streamwater at downstream sampling point $\left(C_{\text {out }} \times Q_{\text {out }}\right)$.

For COD (Fig. 10), groundwater with higher COD than that of the streamwater flows in and gradually increases the COD in streamwater. Furthermore, this shows that the COD in groundwater is higher downstream than upstream. For $\mathrm{NO}_{3}-\mathrm{N}$ (Fig. 10), the $\mathrm{NO}_{3}-\mathrm{N}$ concentration is lower in the groundwater than in the streamwater, and the $\mathrm{NO}_{3}-\mathrm{N}$ concentration in the stream decreases as the water flows downstream.

\subsection{Relationship between Air Temperature and Water Quality Parameters}

To examine seasonal variation in water quality, data collected from 2010 to 2012 were used to calculate a correlation coefficient between air temperature and each water quality parameter. The results are shown in Table 2. For COD, there was a positive correlation at all sampling points, which means that COD becomes higher as the air temperature rises. This may be attributed to the increased rate of leaching of organic matter from soil when the air temperature rises. For $\mathrm{NO}_{3}-\mathrm{N}$, there was a negative correlation at all sampling points, which means that $\mathrm{NO}_{3}-\mathrm{N}$ concentration becomes lower as the air temperature rises. This may be due to plants taking up greater amounts of nitrogen when the air temperature is high as plants undergo more growth. It has been reported that there is little seasonal variation in the water quality of streams in Japanese forest catchments [9]. However, air temperature was found to have an effect on $\mathrm{COD}$ and $\mathrm{NO}_{3}-\mathrm{N}$ in this study. 


\section{Conclusions}

A stream flowing through the Tohoku University Botanical Gardens in Aoba Ward, Sendai city, Miyagi prefecture in Japan was studied in order to understand the factors affecting water quality of the stretch of a stream flowing through a forest.

COD increased with downstream flow. This may be attributed to the high organic content in the downstream soil.

$\mathrm{NO}_{3}-\mathrm{N}$ decreased with the downstream flow. This may be attributed to the sediment being in an oxidized state upstream and reduced state downstream. Furthermore, it was shown that COD increases when air temperature rises, but $\mathrm{NO}_{3}-\mathrm{N}$ decreases when air temperature rises.

\section{References}

[1] Kunimatsu, T., and Sudo, M. 1997. "Measurement and Evaluation of Nutrient Runoff Loads from Mountainous Forested Lands.” Journal of Japan Society on Water Environment 20 (12): 810-815.

[2] Haga, H., and Nishida, K. 2007. "Individuality and Distribution Pattern of Riparian Wetlands Controlling Longitudinal Change in Dissolved Organic Carbon
Concentration in a Forested Stream.” Journal of Japan Society on Water Environment 30 (9): 521-526.

[3] Haga, H., Nishida, K., and Sakamoto, Y. 2007. "Effects of Flow Paths on Dissolved Organic Carbon Concentrations in a Forest Stream.” Journal of Japan Society on Water Environment 30 (10): 573-578.

[4] Olivier, H. 2013. "Redox Potential $\left(\mathrm{E}_{\mathrm{h}}\right)$ and $\mathrm{pH}$ as Drivers of Soil/Plant/Microorganism System: A Transdisciplinary Overview Pointing to Integrative Opportunities for Agronomy.” Plant Soil 362: 389-417.

[5] Nakayama, M., Enari, K., and Kohama, A. 2010. "Behavior of Leachate Permeating into Soil and Effects of pH and CEC.” Sustain. Environ. Res. 20 (5): 299-303.

[6] Haga, H., Nishida K., Fujita, M., and Sakamoto, Y. 2007. "Contribution of Surface Soil Waters to Changes in Nitrate and Dissolved Organic Carbon Concentration in Riparian Wetland Streams.” Journal of Japan Society on Water Environment 30 (4): 213-218.

[7] Ohte, N. 2012. "Implication of Seasonal Variation in Nitrate Export from Forested Ecosystems: A Review from the Hydrological Perspective of Ecosystem Dynamics.” Ecol. Res. 27: 657-665.

[8] Ohrui, K., and Myron, J. M. 1997. "Nitrogen Saturation in Japanese Forested Watersheds.” Ecol. Appl. 7: 391-401.

[9] Ohrui, K. 1997. "Nitrogen Saturation in Forest Ecosystems: The Existing Condition in Japan." The Japanese Society of Environment 39 (1): 1-9. 